\title{
A redescription of well-known pseudoscorpion species, diplotemnus insolitus chamberlin (pseudoscorpiones; atemnidae) based on the specimens collected from Iran
}

Keywords: arachnida, pseudoscorpions, miratemninae, Kazakhstan, bulgaria

Abbreviations: eb, external basal; esb, external sub basal; $i b$, internal basal; isb, internal su basal; ist, internal sub terminal; est, external sub terminal; $i$, internal terminal; et, external terminal; $t$, terminal; $b$, basal; $s b$, sub basal; st, sub terminal

\section{Introduction}

Atemnines can be widely found in most regions of the world whereas miratemnines are more restricted to Africa, southern Europe, central Asia, North America and South America. Only nine species belong to six genera of the Family Atemnidae Kishida, 1929 have been since reported from the Middle East and central Asia: Tullgrenius afghanicus Beier, 1959 and Oratemnus afghanicus Beier, 1959 from Afghanistan, Mesatemnus cyprianus (Beier and Turk, 1952) from Cyprus, Paratemnoides insularis (Banks, 1902) from Ecuador and Turkey, Diplotemnus egregius Beier, 1959 from Afghanistan and Tajikistan, Diplotemnus insolitus Chamberlin, 1933 from Afghanistan, Azerbaijan, Iran, Kazakhstan, Kirghizstan, Tajikistan, Turkey and Uzbekistan, Atemnus letourneuxi (Simon, 1881) from Yemen and Egypt, Atemnus syriacus (Beier, 1955) from Israel, Turkey and Syria and Atemnus politus (Simon, 1878) from Afghanistan, Azerbaijan, Iran, Libya, Kirghizstan, Kazakhstan, Morocco, Tajikistan, Turkey, Pakistan, Syria and Uzbekistan. ${ }^{1}$ Diplotemnus insolitus is the wide species of this family which can be collected from various habitats. This species has been reported from different places around the world those are being mentioned here-under: Afghanistan, Algeria, Azerbaijan, Bulgaria, Chad, China, India, Kazakhstan, Kyrgyzstan, Mongolia, Slovakia, Spain, Sudan, Tajikistan, Turkey, Turkmenistan, Uzbekistan and Iran. The first specimens belong to this species were reported from Kabul or Lahore in India (unspecified locality in the north-west Himalayas) by Chamberlin. ${ }^{2}$ Beier $^{3}$ has reported Diplotemnus piger (Simon, 1878) from Shiraz-southern Iran for the first time. Now, this species is known as synonym by Diplotemnus insolitus Chamberlin. ${ }^{4,5}$ In this survey, the nymphs and adults collected from central and southern parts of Iran are shortly redescribed, illustrated and also, their geographical distribution pattern is given.

\section{Material and methods}

The materials used in this study were preserved in $70 \%$ ethanol and prepared for study as follows: The pedipalps, chelicera, first and fourth legs were dissected, cleared with $60 \%$ lactic acid, and mounted on glass microscope slides in Hoyer's medium. The specimens were examined and illustrated with an Olympus BH-2 compound microscope and drawing by using tube attachment. The specimens are lodged in Collection of the Acarology Laboratory, Islamic
Volume 3 Issue I - 2018

Mahrad Nassirkhani

Islamic Azad University, Iran

Correspondence: Mahrad Nassirkhani, Entomology Department, Faculty of Agriculture and Natural Resources, Islamic Azad University, Arak branch, Arak, Iran, Tel +989131416830, Email greenartificialturfgrass@gmail.com

Received: October 29, 2017| Published: February 09, 2018

Azad University of Arak, Iran. The morphological terminology and mensuration follow ${ }^{6-9}$ (Figure 1-24).

\section{Material examined}

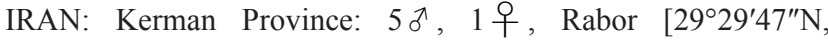
$56^{\circ} 26^{\prime} 18^{\prime \prime}$ E, altitude 2000m], Baft, dry leaf litter, May 14 2011, leg M

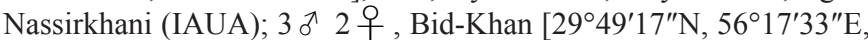
altitude 2600m], Bardsir, moisture leaf litter, June 15 2011, leg M Nassirkhani (IAUA); 3 지, 1 우, 2 protonymphs, 1 deutonymph, 5 tritonymphs, Sar-cheshmeh $\left[29^{\circ} 56^{\prime} 17^{\prime \prime} \mathrm{N}, 55^{\circ} 52^{\prime} 02^{\prime \prime} \mathrm{E}\right.$, altitude 2800m], April 9 2012, leg M Nassirkhani (IAUA); 6ठ, Rabor [29 $30^{\prime} 12^{\prime \prime} \mathrm{N}, 56^{\circ} 23^{\prime} 20^{\prime \prime} \mathrm{E}$, altitude $\left.2500 \mathrm{~m}\right]$, Baft, dry litter, July 20 2013, leg M Nassirkhani (IAUA); Isfahan Province: 2 ๙ , 2 우, Badroud [undetermined], dry leaf litter, May 8 2015. Yazd Province: $1 \mathrm{o}^{\top}$, Kalmand Protected Area $\left[31^{\circ} 05^{\prime} 45^{\prime \prime} \mathrm{N}, 54^{\circ} 27^{\prime} 51^{\prime \prime} \mathrm{E}\right.$, altitude 2160m], Mehriz, under stone, May 6 2015, leg M Nassirkhani (IAUA); 2 우, Nation Park [undetermined], Yazd, leaf litter, May 5 2015, leg M Nassirkhani (IAUA).

\section{Diagnosis}

This species can be separated from $D$ vachoni Dumitresco and Orghidan, ${ }^{10} 1969$ from France, Yougoslavia and Bulgaria by differences in the chelal shape (Figure 4). Diplotemnus pieperi Helversen, 1965 from Pitao-Grande is similar to $D$ insolitus and $D$ vachoni but can be distinguished by the longer $\left(1.20 \mathrm{~mm} \sigma^{\star}\right)$ and stouter $(0.54 \mathrm{~mm}$, ð ) pedipalpal femur. ${ }^{11}$ Trichobothrium seta st of $D$ pinguis Beier, 1955 from Cape-Agulhas is situated closer to $s b$ than $t$ (Figure 26) whereas in D Insolitus, st located at the middle between $t$ and $s b$. In addition, the female type of $D$ pinguis is very smaller than the females of $D$ insolitus, e.g. pedipalpal femur length is $0.58 \mathrm{~mm}$. Diplotemnus rudebecki Beier, 1955 from South Africa can be separated from $D$ insolitus those are collected from Iran by the tarsus IV ratio $\left(3.5 \mathrm{x},{ }^{\curvearrowright}\right.$ ), the stouter chela $\left(0.54 \mathrm{~mm}, \sigma^{\pi}\right)$, and the position of trichobothrium it that is situated medially between $e t$ and ist (Figure 27). The chelal ratio of $D$ namaquensis Beier 1947 from Namaqualand is very similar $\left(1.24 / 0.40 \mathrm{~mm}, \sigma^{\pi}\right)$ to that of $D$ insolitus. This species is recognized 
by the narrow pedipalpal patella $\left(0.85 / 0.33 \mathrm{~mm},{ }^{\lambda}\right)$, and the position of trichobothrium it that is closer to et than ist and the ratio of tarsus IV $\left(4.3 \mathrm{x}, 0^{\text {๙ }}\right)$. Diplotemnus rothi Muchmore, 1975 from south-western USA can be easily recognized by the stouter chela $\left(0.63-0.66 \mathrm{~mm}, \sigma^{\lambda}\right.$ ), tarsus IV ratio $\left(4.15, \sigma^{\Uparrow}\right)$ and the position of the nodus ramosus that is located between trichobothrium et and it (Figure 4) while the nodus ramosus of $D$ insolitus is longer and situated between et and est.

\section{Description}

\section{Protonymph}

Carapace: (Figures 1-5), Body length: 1.52-1.57 mm; Finely granulate; L/W 0.77-1.00; with 2 well developed eyes; eyes very close to anterior margin; anterior and posterior margins with 4 setae, of which 2 very short; transverse furrows absent. ${ }^{12-15}$

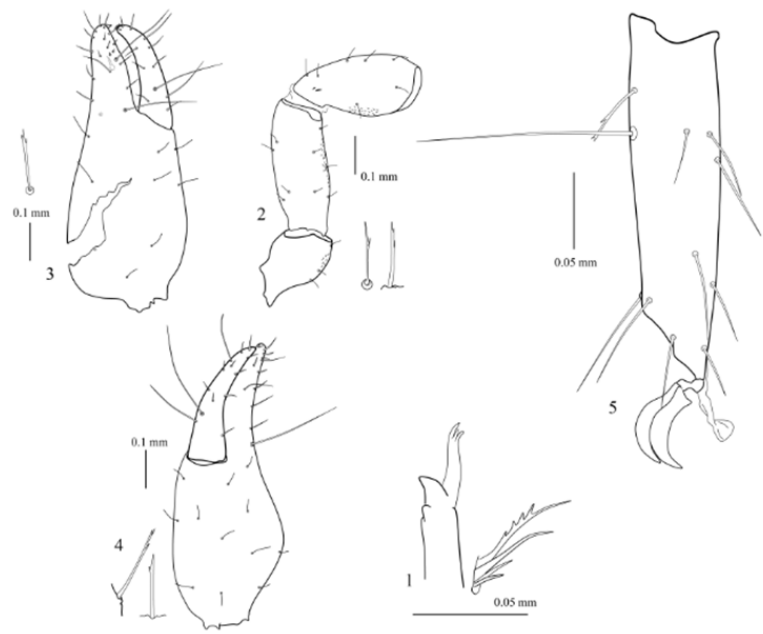

Figure I-5 Diplotemnus insolitus Chamberlin, 1933, protonymph: I. Galea and rallum;2. Basal segments of pedipalp; 3. Right chela, lateral aspect; 4 . Right chela, retrolateral dorsal aspect; 5. Tarsus IV.

Tergites: Slightly sclerotized; smooth; without median suture line;

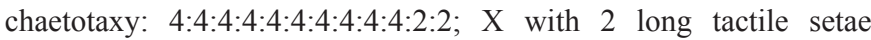
situated latero-medially; XI with 2 median tactile setae.

Sternites: Smooth; without median suture line; $\mathrm{X}$ and XI with 2 long tactile setae situated medially; chaetotaxy: 2:(0)2(0):(1)2(1):4:4:4:4: $4: 4: 4: 4: 2$.

\section{Pleural membrane: striate}

i. Chelicera: Hand with 4 setae, sub-basal seta absent; galeal seta absent; galea with 2-3 rami (Figure 1); serrula exterior with 1517 blades; rallum with 4 blades, basal blade shortest and distal blade longest with lateral denticulations; fixed finger with 6 teeth; movable finger with two blunt sub-apical teeth.

ii. Pedipalps: Trochanter, femur and patella finely granulate; trochanter with a dorsal hump (Figure 2), L/W 1.23-1.53; femur L/W 2.36-3.46; patella with 2 basal lyrifissures, L/W 1.93-1.87; chela (with pedicel) L/W 2.91-3.04; chela (without pedicel) L/W 2.82-2.90; hand (with pedicel) L/W 1.86-1.90; hand (with pedicel) 1.43-1.44 times longer than movable finger; fixed finger with 20-21 and movable finger with 2223 teeth; trichobothrial pattern shown in Figure 3 \& 4; nodus ramosus situated proximal to et. iii. Legs: Sub-terminal seta simple; claws symmetrical; Arolia simple; Leg I: tibia L/D 2.88-3.40; tarsus L/D 4.00-4.70. Leg IV: tibia L/D 3.57; tarsus with one tactile setae situated proximal to middle of the segment (Figure 5), L/D 3.67-4.40.

Dimensions in mm: Carapace: 0.42-0.50/0.50-0.54; Pedipalp: trochanter $0.16-0.20 / 0.13$; femur $0.31-0.32 / 0.13-0.15$; patella 0.30 $0.31 / 0.16$; chela (with pedicel) $0.67-0.75 / 0.22-0.23$; chela (without pedicel) 0.64-0.70; hand (with pedicel) L.0.42-0.43; movable finger L. 0.29-0.30. Leg I: femur 0.13-0.14/0.07-0.08; patella 0.17-0.18/0.060.07 ; tibia $0.16-0.17 / 0.05-0.06$; tarsus $0.19-0.20 / 0.04-0.05$. Leg IV: femur $0.13-0.14 / 0.09-0.10$; patella $0.24 / 0.11$; tibia $0.25 / 0.07$; tarsus 0.22/0.05-0.06.

\section{Deutonymph}

Body length: $1.82 \mathrm{~mm}$

i. Carapace: Finely granulate; as long as width; with 2 well developed eyes; anterior and posterior margins with 6 setae; transverse furrows present.

ii. Tergites: Slightly sclerotized; finely granulate; with median suture line, I-VI distinctly divided, VII-X incompletely divided, XI not divided; chaetotaxy: 6:6:6:6:6:6:6:6:6:6:4:2; $\mathrm{X}$ with 2 long tactile setae situated latero-medially; XI with 2 median tactile setae.

iii. Sternites: Smooth; without median suture line; X and XI with 2 long tactile setae situated medially; chaetotaxy: 3:(0)4(0):(1) $2(1): 6: 6: 5: 4: 6: 6: 6: 6: 2$

\section{iv. Pleural membrane: Striate}

v. Chelicera: Hand with 5 setae; galeal seta present; galea with 3 rami; serrula exterior with 17 blades; rallum with 4 blades, distal blade longest with lateral denticulations (Figure 6); fixed finger with 6 teeth; movable finger with two blunt sub-apical lobe.
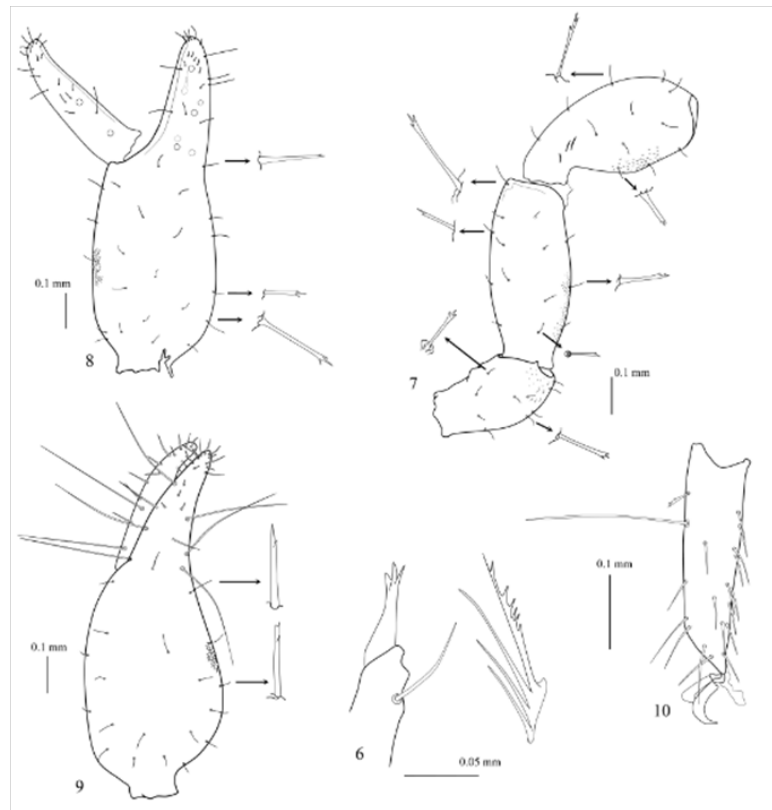

Figure 6 - 10 Diplotemnus insolitus Chamberlin, I 933, deutonymph: I I. Galea and rallum; I 2. Basal segments of pedipalp; I3. Left chela, lateral aspect; I4. Left chela, dorsal aspect; I5. Tarsus IV. 
vi. Pedipalps: Sclerotized; granulate; trochanter with a dorsal hump, L/W 2.10; femur L/W 2.23; patella with 3 basal lyrifissures, L/W 2.04; chela (with pedicel) L/W 2.97; chela (without pedicel) L/W 2.75; hand (with pedicel) L/W 1.87; hand (with pedicel) 1.46 times longer than movable finger; fixed finger with 22 and movable finger with 26 teeth; trichobothrial pattern shown in figures 8-9; nodus ramosus situated between et and it.

vii. Legs: Sub-terminal seta simple; claws symmetrical; Arolia simple; Leg I: tibia L/D 3.00; tarsus L/D 4.33. Leg IV: tibia L/D 3.73; tarsus with one tactile setae situated proximal to middle of the segment (Figure 10), L/D 3.87.

viii. Dimensions in mm: Carapace: $0.60 / 0.60$; Pedipalp: trochanter $0.40 / 0.19$; femur $0.49 / 0.22$; patella $0.51 / 0.25$; chela (with pedicel) $0.95 / 0.32$; chela (without pedicel) 0.88 ; hand (with pedicel) L.0.60; movable finger L. 0.41. Leg I: femur $0.19 / 0.12$; patella $0.27 / 0.11$; tibia $0.27 / 0.09$; tarsus $0.26 / 0.06$ Leg IV: femur $0.21 / 0.15$; patella $0.41 / 0.17$; tibia $0.41 / 0.11$; tarsus $0.31 / 0.08$.

\section{Tritonymphs}

Body length: $2.77-3.00 \mathrm{~mm}$

i. Carapace: L/W 1.00-1.10; with 2 developed corneate eyes; anterior margin with 6 setae; posterior margin with 7-9 setae; with 2 distinct transverse furrows, anterior furrow slightly curved basally (U-shaped) and extending to lateral margins and situated medially, posterior furrow shorter, wider and not extending laterally.

ii. Tergites: Sclerotized and granulate; I-X divided with median suture line, XI not divided; chaetotaxy: 9:8:9:9:8:9:9:7:9:7:7:2; half-tergites III to XI with one lateral discal seta; each halftergite $\mathrm{X}$ with 2 long tactile setae situated laterally and medially; each half-tergite XI with a long tactile setae, situated medially.

iii. Sternites: Smooth; III-X divided with median suture line; sternites II and III deformed and shaped primary genital pore; chaetotaxy: 2:(2)6(2):(1)8(1):9:9:8:10:9:10:10:2; each halfsternite $\mathrm{X}$ with a long tactile setae situated medially; each halfsternite XI with 2 tactile setae situated laterally and medially.

\section{iv. Pleural membrane: Striate}

v. Chelicera: Hand with 5 setae; galeal seta present; galea with 3-4 rami (Figure 11); serrula exterior with 17-20 blades; rallum with 4 blades, distal blade longest with lateral denticulations (Figure 11); fixed finger with 6 teeth, distal teeth short and acute, 2 median teeth bigger and not sharp, basal teeth medium in size and acute; movable finger with one sub-apical blunt tooth.

vi. Pedipalps: Sclerotized and granulate; trochanter with 2 dorsal humps (Figure 12), L/W 1.80-2.00; femur L/W 2.302.91; patella with two lyrifissures, L/W 2.06-2.22; chela (with pedicel) L/W 3.12-3.56; chela (without pedicel) L/W 2.923.33; hand (with pedicel) L/W 1.90-2.92; hand (with pedicel) 1.43-1.61 times longer than movable finger; trichobothrial pattern shown in Figure 13-14; nodus ramosus present in fixed finger, situated distinctly at same level as it; fixed finger with 25-27 and movable finger with 27-30 teeth. vii. Legs: Sub-terminal seta simple; claws symmetrical; Arolia simple; Leg I: tibia L/W 3.70-4.37; tarsus L/W 4.28-5.00. Leg IV: tibia L/W 4.25-4.90; tarsus with one tactile setae situated proximal to middle of segment (Figure 15), L/W 4.12-4.50.

viii. Dimensions in mm: Carapace: 0.80-0.90/0.75-0.90; Pedipalp: trochanter $0.36-0.38 / 0.19-0.21$; femur $0.64-0.69 / 0.22-0.30$; patella $0.60-0.64 / 0.27-0.31$; chela (with pedicel) 1.071.25/0.30-0.40; chela (without pedicel) 1.00-1.17; hand (with pedicel) L.0.71-0.76; movable finger L. 0.44-0.53. Leg I: femur $0.22-0.23 / 0.14-0.15$; patella $0.34-0.35 / 0.12-0.13$; tibia 0.34-0.36/0.08-0.09; tarsus 0.30-0.31/0.06-0.07. Leg IV: femur $0.22-0.25 / 0.14-0.15$; patella $0.48-0.60 / 0.18-0.20$; tibia 0.49 $0.52 / 0.10-0.12$; tarsus $0.33-0.35 / 0.08$.
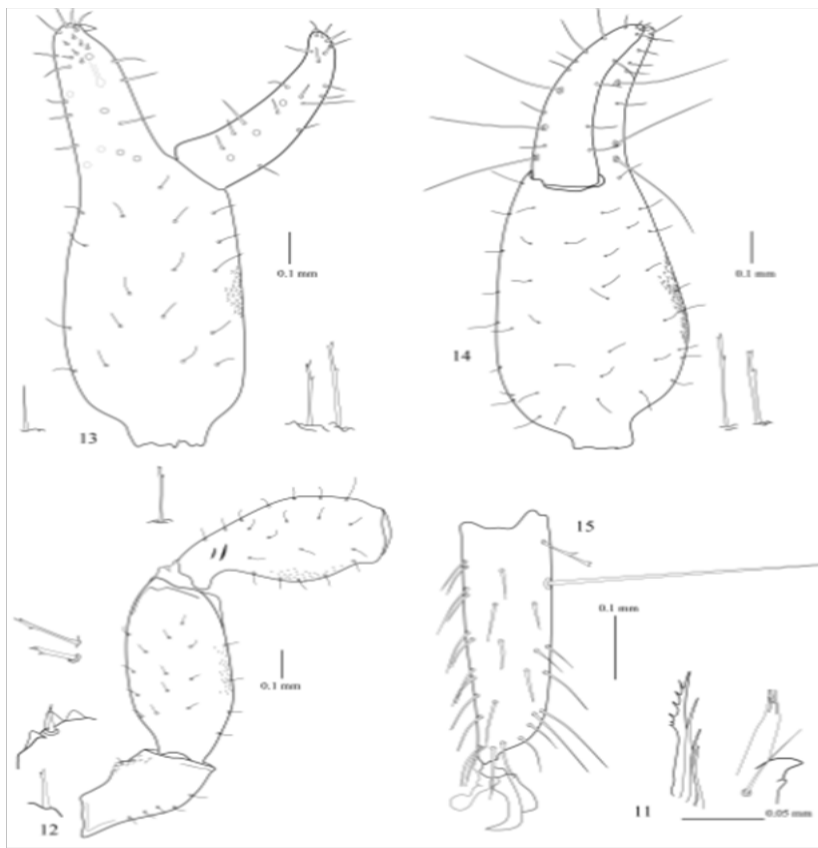

Figures I I-I 5 Diplotemnus insolitus Chamberlin, 1933, tritonymph: I. Galea and rallum; 2. Basal segments of pedipalp; 3. Right chela, lateral aspect; 4. Left chela, retrolateral dorsal aspect; 5. Tarsus IV.

\section{Adults}

Body length: $3.12-3.70 \mathrm{~mm}$

i. Carapace: Entirely granulate; 1.03-1.22 times longer than width; with 2 well developed corneate eyes (Figure 16); anterior margin with 6-9 setae, 2 very short setae situated medially; posterior margin with 9-10 setae; with 2 distinct transverse furrows.

ii. Tergites: Roughly sclerotized; intensively granulate; I and II not divided, III-X divided with distinct median suture line, XI divided incompletely (In a number of the examined specimens: I-X divided with distinct median suture line); chaetotaxy: 8-10:7-11:8-10:10:9-12:11-12:12:12:12:10-12:6-7:2; halftergites IV-XI with one lateral discal seta; each half-tergite $\mathrm{X}$ with 2 long tactile setae situated laterally; each half-tergite XI with 2 median tactile setae.

iii. Sternites: Lightly sclerotized; slightly granulate; IV-X divided with narrow median line; anterior operculum with 13-16 and posterior operculum with 10-16 simple setae ( 9 anterior 
operculum with 6-8 and posterior operculum with 8-9 simple setae); anterior spiracle with 2-3 suprastigmal setae (Figure 17) (우 anterior spiracle with 1-3 suprastigmal setae (Figure 18); each half-sternite $\mathrm{X}$ with 2 slightly long setae situated laterally and medially; each half-sternite XI with one long tactile setae situated medially; cribriform plates and spermatheca shown in Figure 20.
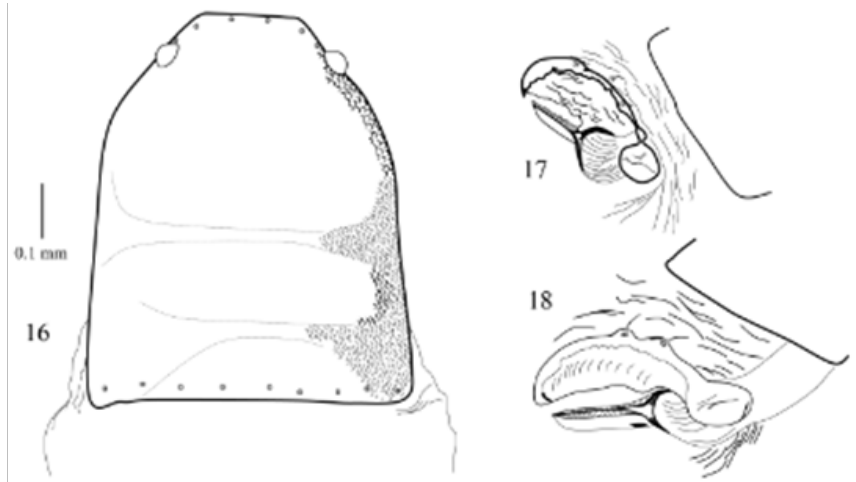

Figures 16-18 Diplotemnus insolitus Chamberlin, 1933, from SarcheshmeKerman Province, 우 : 16. Carapace, dorsal aspect; 17. Anterior spiracle ( $\left.0^{\Uparrow}\right)$; 18. Anterior spiracle (우).

\section{iv. Pleural membrane: Striate}

v. Chelicera: Hand with 5 setae; galeal seta present; galea with 4-6 rami; serrula exterior with 22-27 blades; rallum with 4 blades, distal blade longest with lateral denticulations (Figure 19); fixed finger with 7 teeth, distal teeth short and acute, median teeth bigger and basal teeth medium in size; movable finger with one sub-apical tooth.

vi. Pedipalps: Roughly granulate (Figure 21); chelal hand (with pedicel) 1.60-1.70 longer than movable finger; fixed finger with 27-30 and movable finger with 29-32 similar shape teeth; trichobothrial pattern shown in Figure $22 \& 23$; nodus ramosus present in fixed finger, situated distinctly between it and et.

vii. Legs: Sub-terminal seta simple; claws symmetrical; Arolia simple; tarsus IV with one tactile seta situated proximal to middle of the segment (Figure 24).

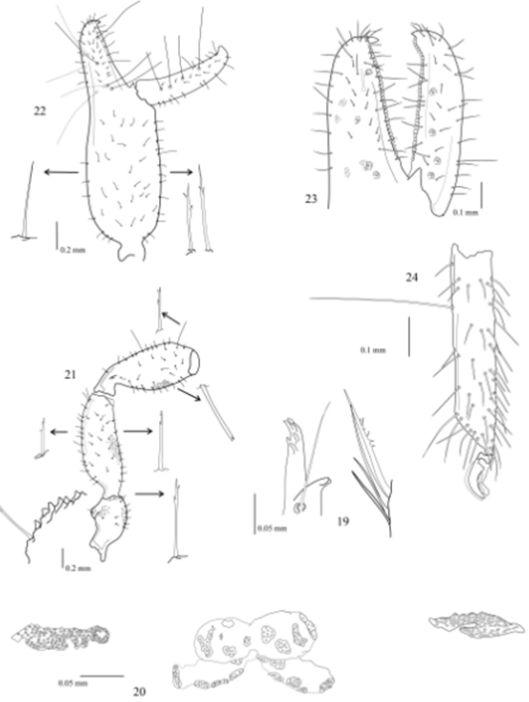

Figures 19-24 Diplotemnus insolitus Chamberlin, 1933 from Badroud-Isfahan Province, 우: 19. Galea and rallum; 20. Genitalia (sowing cribriform plates and spermathecae); 2I. Basal segments of pedipalp; 22. Right chela, lateral aspect; 23. Right chelal fingers (showing trichobothrial pattern, position of nodus ramosus, chelal teeth, and sensory setae), lateral aspect; 24. Tarsus IV.

\section{Remarks}

Comparison of the newly collected specimens from Iran to Chamberlin's description shows many similarities, but slight differences in the chelal ratios present (Table $1 \& 2$ ). The chela of the type specimens is stouter $\left(3.05 \mathrm{x}, \sigma^{\pi}\right)$ than that of the Iranian specimens (3.59-4.26x, $\left.\circlearrowleft^{\star}\right)$. As part of a study of Central Asian on pseudoscorpions fauna, Dashdamirov \& Schawaller Dashdamirov ${ }^{4}$ reported that D Afghanicus 1959, D lindbergi Beier, 1960, D Ophthalmicus Redikorzev, 1949 and D Persicus Redikorzev, 1934 are synonyms of $D$ insolitus. This report is signified to presence of the wide ranges between the values of pedipalpal size and proportions. The femur and chelal ratios of $D$ afghanicus were reported by Beier ${ }^{15}$ as follows: femur is $2.80 \mathrm{x}\left(\delta^{\star}\right)$ and chela (with pedicel) $3.60 \mathrm{x}\left(\delta^{\star}\right)$, while femur and chelal (with pedicel) ratios of Iranian specimens are 2.86-3.36x (ð) and 3.41-4.26x (ð). So, the Iranian specimens are similar to D Afghanicus.

Table I Dimension (in $\mathrm{mm}$ ) and chelal teeth numbers of morphological characters in Diplotemnus insolitus Chamberlin, I933

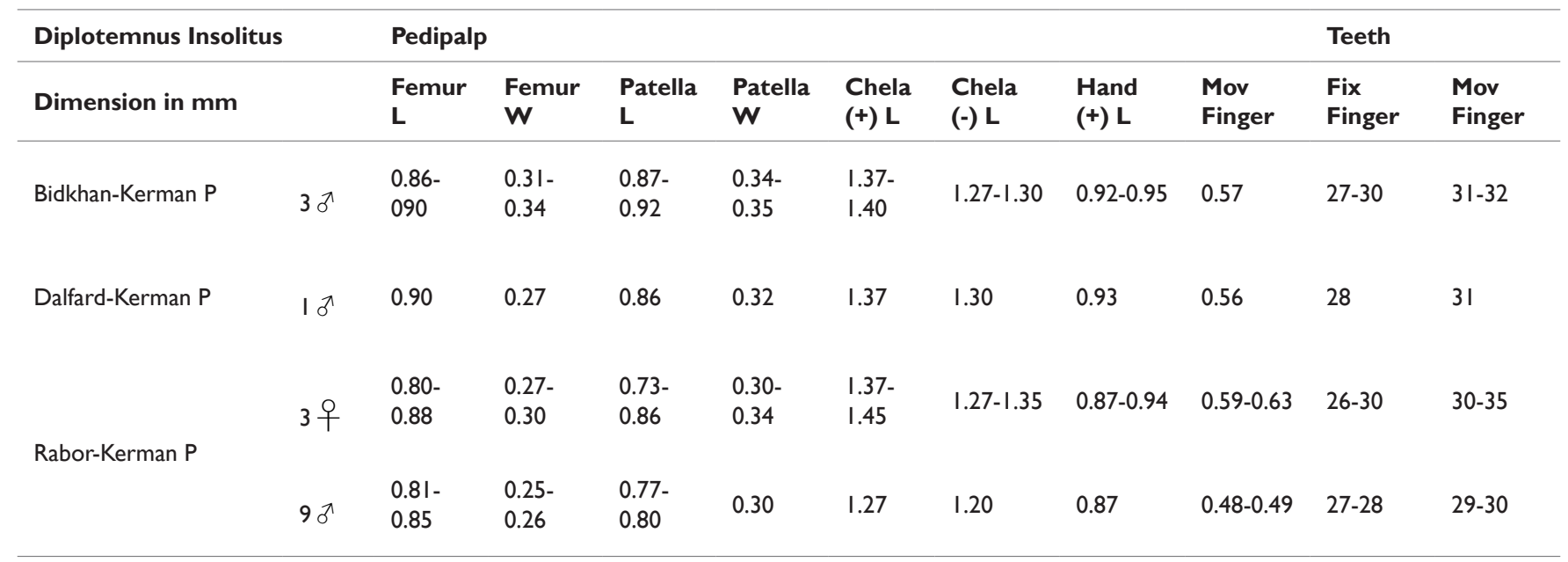


Table Continued.

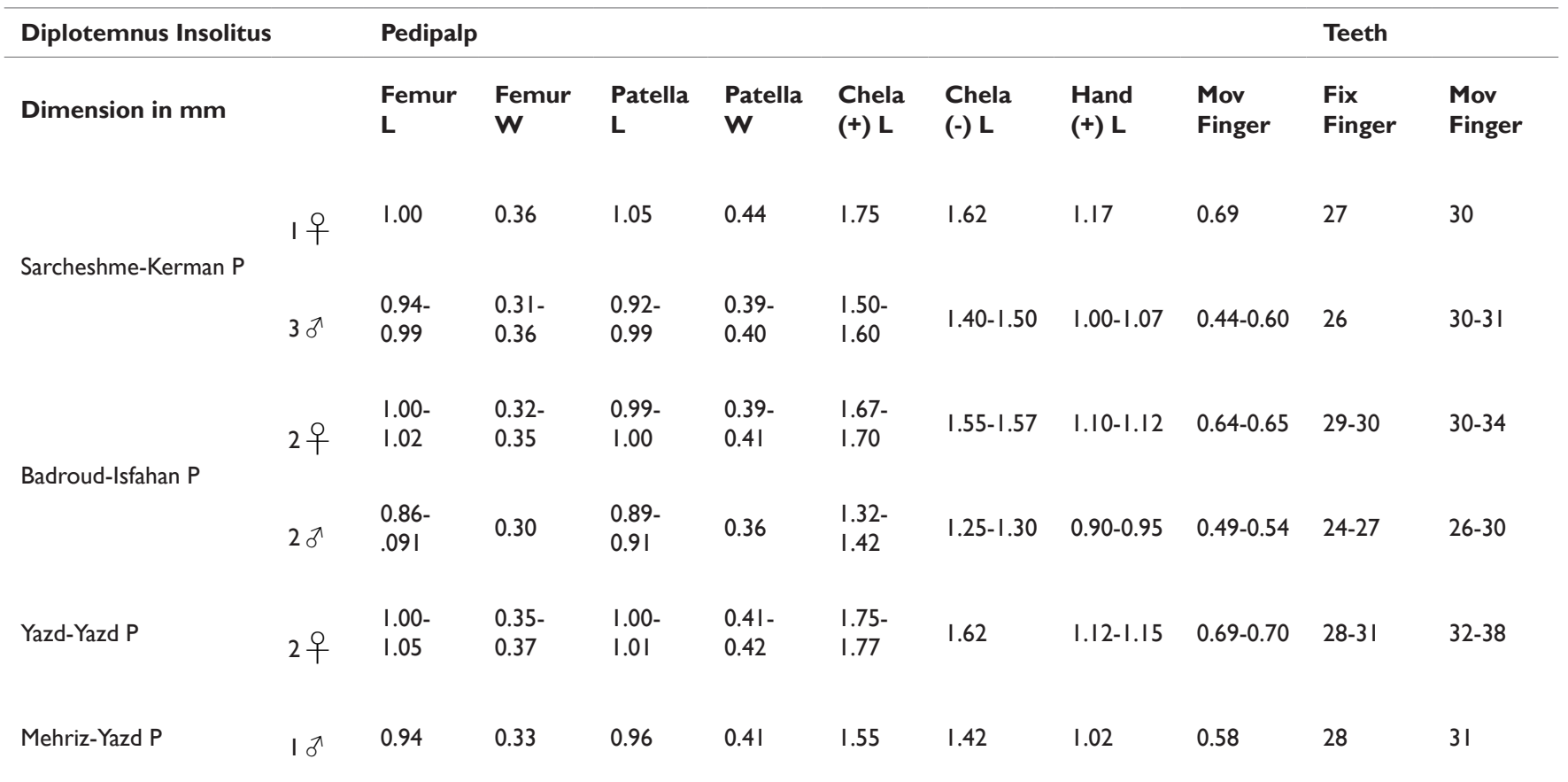

[+]:With pedicel; [-]:Without pedicel; Mov.finger [-]: Movable finger; Fix finger [-]: fixed finger

Table 2 Ratios of morphological characters in Diplotemnus insolitus Chamberlin, 1933

\begin{tabular}{|c|c|c|c|c|c|c|c|c|c|c|c|}
\hline \multirow{2}{*}{\multicolumn{2}{|c|}{$\begin{array}{l}\text { Diplotemnus Insolitus } \\
\text { Ratios }\end{array}$}} & \multicolumn{5}{|c|}{ Pedipalp } & \multicolumn{2}{|c|}{ Leg I } & \multicolumn{2}{|c|}{ Leg IV } & \multirow{2}{*}{$\begin{array}{l}\text { Body } \\
\text { Carapace }\end{array}$} \\
\hline & & Femur & Patella & $\begin{array}{l}\text { Chela } \\
(+)\end{array}$ & Chela (-) & Hand $(+)$ & Tibia & Tarsus & Tibia & Tarsus & \\
\hline Bidkhan-Kerman P & $3 \pi$ & $\begin{array}{l}2.86- \\
2.90\end{array}$ & $\begin{array}{l}2.55- \\
2.62\end{array}$ & $3.59-3.60$ & $3.33-3.34$ & $2.42-2.43$ & $\begin{array}{l}4.90- \\
5.09\end{array}$ & $\begin{array}{l}4.82- \\
4.94\end{array}$ & $\begin{array}{l}5.42- \\
5.84\end{array}$ & $\begin{array}{l}5.11- \\
5.22\end{array}$ & $1.05-1.06$ \\
\hline Dalfard-Kerman P & $1 \sigma^{\pi}$ & 3.33 & 2.69 & 3.80 & 3.61 & 2.58 & 4.72 & 4.87 & 5.61 & 5.11 & 1.03 \\
\hline \multirow[b]{2}{*}{ Rabor-Kerman P } & 3 우 & $\begin{array}{l}2.93- \\
3.14\end{array}$ & $\begin{array}{l}2.43- \\
2.57\end{array}$ & $3.33-3.62$ & $3.09-3.37$ & $2.14-2.35$ & $\begin{array}{l}4.80- \\
4.90\end{array}$ & $\begin{array}{l}4.75- \\
5.14\end{array}$ & $\begin{array}{l}5.50- \\
6.00\end{array}$ & $\begin{array}{l}4.55- \\
5.00\end{array}$ & $1.03-1.20$ \\
\hline & $5 \circlearrowleft$ & $\begin{array}{l}3.11- \\
3.36\end{array}$ & $\begin{array}{l}2.56- \\
2.66\end{array}$ & $4.09-4.26$ & $3.87-4.00$ & $2.80-2.90$ & 4.70 & 5.28 & 5.58 & $\begin{array}{l}5.37- \\
5.50\end{array}$ & $1.20-1.22$ \\
\hline \multirow[b]{2}{*}{ Satcheshme-Kerman P } & I우 & 2.78 & 2.38 & 3.02 & 2.79 & 2.02 & 4.00 & 4.50 & 4.47 & 4.33 & 1.25 \\
\hline & $3 \pi$ & $\begin{array}{l}2.75- \\
3.03\end{array}$ & $\begin{array}{l}2.34- \\
2.47\end{array}$ & $3.41-3.55$ & $3.18-3.33$ & $2.27-2.38$ & $\begin{array}{l}4.30- \\
5.00\end{array}$ & $\begin{array}{l}4.66- \\
4.78\end{array}$ & $\begin{array}{l}4.76- \\
5.44\end{array}$ & $\begin{array}{l}4.64- \\
5.00\end{array}$ & $1.12-1.22$ \\
\hline \multirow[b]{2}{*}{ Badroud-Isfahan P } & 2우 & $\begin{array}{l}2.85- \\
3.19\end{array}$ & $\begin{array}{l}2.41- \\
2.56\end{array}$ & $3.33-3.48$ & $3.08-3.22$ & $2.19-2.29$ & $\begin{array}{l}4.15- \\
4.50\end{array}$ & $\begin{array}{l}4.30- \\
4.77\end{array}$ & $\begin{array}{l}4.66- \\
5.46\end{array}$ & $\begin{array}{l}4.82- \\
5.20\end{array}$ & $1.04-1.12$ \\
\hline & $2 \pi$ & $\begin{array}{l}2.87- \\
3.03\end{array}$ & $\begin{array}{l}2.53- \\
2.72\end{array}$ & $3.57-3.83$ & $3.38-3.51$ & $2.43-2.57$ & $\begin{array}{l}4.08- \\
4.25\end{array}$ & $\begin{array}{l}4.11- \\
4.44\end{array}$ & $\begin{array}{l}5.00- \\
5.43\end{array}$ & $\begin{array}{l}4.80- \\
4.89\end{array}$ & $1.10-1.16$ \\
\hline Yazd-Yazd P & 2우 & $\begin{array}{l}2.70- \\
3.00\end{array}$ & $\begin{array}{l}2.40- \\
2.44\end{array}$ & $3.24-3.28$ & 3.00 & $2.07-2.13$ & $\begin{array}{l}4.92- \\
5.08\end{array}$ & $\begin{array}{l}5.11- \\
5.33\end{array}$ & 5.56 & $\begin{array}{l}4.63- \\
5.60\end{array}$ & $0.98-1.00$ \\
\hline Mehriz-Yazd P & Ið & 2.85 & 2.34 & 3.44 & 3.15 & 2.26 & 4.28 & 4.00 & 5.00 & 4.45 & 1.07 \\
\hline
\end{tabular}

For abbreviations see Table I.

Citation: Nassirkhani M.A redescription of well-known pseudoscorpion species, diplotemnus insolitus chamberlin (pseudoscorpiones; atemnidae) based on the specimens collected from Iran. Int J Avian \& Wildlife Biol. 20I8;3(I):68-73. DOI: 10.15406/ijawb.2018.03.00057 
In due attention to the geographical distribution pattern of $D$ Insolitus in central and southern Iran (Figure 25), it is logically resulted that the studied pseudoscorpions are adapted to survive in xerotic habitats which are generally characterized by little liquid available water, dry climates, and hot temperatures.

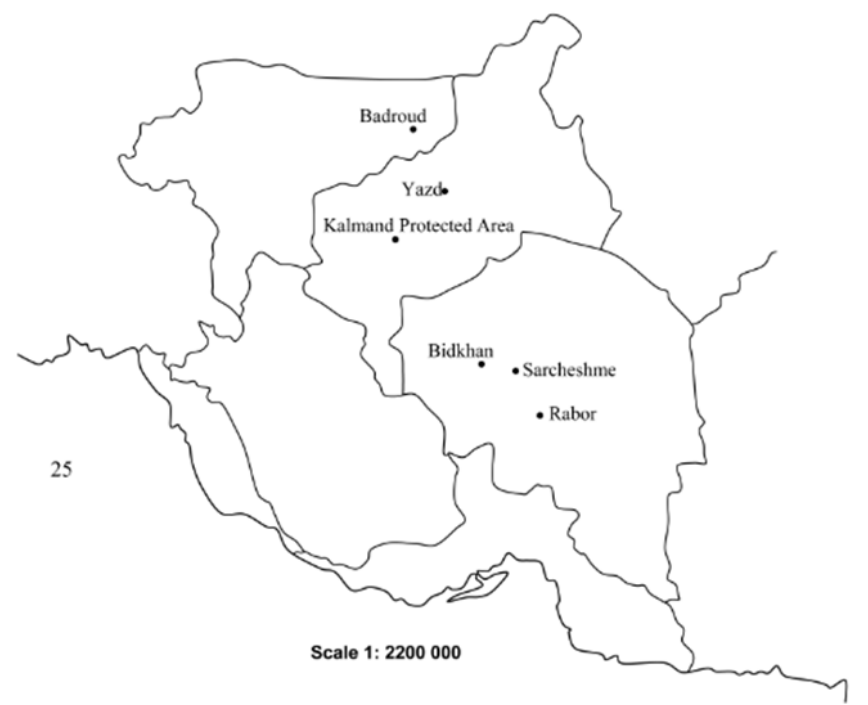

Figure 25 Collecting localities of diplotemnus insolitus chamberlin, 1933 in central and southern Iran.

\section{Acknowledgements}

The author is very grateful to Mr Mahmoud Nassirkhani for his assistance.

\section{Conflict of interest}

The author declares that he has no competing interest and has not a financial relationship with the organization that sponsored the research.

\section{References}

1. Harvey MS. Pseudoscorpions of the world. Australia: Government of Western Australia; 2013

2. Chamberlin JC. Some false scorpions of the atemnid subfamily Miratemninae. Annals of the Entomological Society of America. $1933 ; 26(2): 262-268$
3. Beier M. Pseudoscorpions from Iran. Anal Natural History Museum in Vienna. 1971;75:357-366.

4. Dashdamirov S, Schawaller W. Stuttgart Contributions to Natural History. Ser A (biology). 1995;522(24):21-22.

5. Dashdamirov S. Miscellanea chernetologica (Atachnida: Pseudoscorpiones), based on the collection of the Natiral History Museum in Vienna, Part 2. Arthropoda Selecta. 2005;14(4):303-304.

6. Chamberlin JC. The arachnid order Chelonethida. Stanford University Publications. Biological Sciences. 1931;7(1):1-284.

7. Harvey MS. The phylogeny and classification of the Pseudoscorpionida (Chelicerata: Arachnida). Invertebrate Taxonomy. 1992;6:1373-1435.

8. Harvey MS, Ratnaweera PB, Randeniya PV, et al. A new species of the pseudoscorpion genus Megachernes (Pseudoscorpiones:Chernetidae) associated with a threatened Sri Lankan rainforest rodent, with a review of host associations of Megachernes. Journal of Natural History. 2012;46:2519-2535.

9. Judson MLI. A new and endangered species of the pseudoscorpion genus Lagynochthonius from a cave in Vietnam, with notes on chelal morphology and the composition of the Tyrannochthoniini (Arachnida, Chelonethi, Chthoniidae). Zootaxa. 2007;1627:53-68.

10. Dumitresco M, Orghidan T. South deux spéces nouvelles de Pseudoscorpions (Arachnides) Roman lithoclasicoles: Diplotemnus vachoni (Atemnidae) and Dactylochelifer marlausicolus. Bulletin $d u$ Muséum National d'Histoire Naturelle. 1969;2(41):128-134.

11. Helversen O. Einige Pseudoskorpione Von Den Ilhas Selvagens, Scientific Expedition to the Salvage Island. Buletin do Museu Municipal do Funchal. 1963;21:89-103.

12. Beier M. Pseudoscorpionidea, South African Animal Life, Results of the Lund University Expedition in 1950-1951. Sonderabdruck. 1955; 1(62):263-328.

13. Beier M. Zur Kenntnis der Pseudoscorpioniden-Fauna des Südichen Afrika, insbesondere der südwest-und südafrikanischen Trockengebiete. CSIC. 1947;23:285-339.

14. Muchmore WB. Two miratemnid pseudoscorpions from the Western Hemisphere (Pseudoscorpoionida, Miratemnidae). The Southwestern Naturalist. 1975;20(2):231-239.

15. Beier M. Zur Kenntnis der Pseudoscorpioniden-Fauna Afghanistans, Zoologische Jahbücher Systematic. 1959;87(3):257-282. 